\title{
Multifocal Motor Neuropathy: Update on Clinical Characteristics, Pathophysiological Concepts and Therapeutic Options
}

\author{
Sven G. Meuth Christoph Kleinschnitz \\ Department of Neurology, University of Wuerzburg, Wuerzburg, Germany
}

\section{Key Words}

Multifocal motor neuropathy - Conduction block ·

Anti-GM1 antibodies $\cdot$ Ion channels

\begin{abstract}
Multifocal motor neuropathy (MMN) is an acquired immunemediated neuropathy characterized by chronic or stepwise progressive asymmetrical limb weakness without sensory deficits. The upper extremities are more often affected than the lower extremities with distal paresis dominating over proximal paresis. Important diagnostic features are persistent multifocal partial conduction blocks (CBs) and the presence of high-titer anti-GM1 serum antibodies. Motor neuron disease, other chronic dysimmune neuropathies, such as chronic inflammatory demyelinating polyneuropathy and the Lewis-Sumner syndrome (MADSAM neuropathy), are important differential diagnoses. While corticosteroids and plasma exchange are largely ineffective, high-dose intravenous immunoglobulins are regarded as first-line treatment. In spite of significant success in elucidating the underlying disease mechanisms in MMN during the past few years, important pathophysiological issues and the optimum longterm therapy remain to be clarified. The present review summarizes the clinical picture and current pathophysiological concepts of MMN with a special focus on the molecular and electrophysiological basis of CBs and highlights established therapies as well as possible novel treatment options.
\end{abstract}

Copyright $\odot 2010$ S. Karger AG, Basel

\section{KARGER}

Fax +4161306 1234

E-Mail karger@karger.ch

www.karger.com
(C) 2010 S. Karger AG, Basel

0014-3022/10/0634-0193\$26.00/0

Accessible online at:

www.karger.com/ene

\section{Introduction}

More than 20 years ago Roth et al. [1] reported a patient with chronic asymmetric, distal motor neuropathy without sensory loss. Electrophysiological examination revealed proximal multifocal persistent conduction blocks (CBs) outside the common entrapment sites. Soon afterwards, others described individuals with similar characteristics $[2,3]$. The term 'multifocal motor neuropathy' (MMN) was coined in 1988 by Pestronk et al. [4] who first recognized the association of MMN with antiGM1-IgM antibodies and the responsiveness to immunemodulating therapies. Since then, systematic clinical and electrophysiological evaluation of larger patient cohorts increased our pathophysiological understanding of MMN and paved the way for more effective treatments [5-10]. Especially the successful application of intravenous immunoglobulins (IVIgs) marked a cornerstone in MMN therapy and is nowadays regarded as the gold standard [10-16]. More recently, diagnostic criteria for this rare neuropathy have been proposed by various European and American neurological associations $[17,18]$ which help to delineate MMN from other neuropathies such as chronic inflammatory demyelinating polyneuropathy (CIDP) or multifocal acquired demyelinating sensory and motor (MADSAM) neuropathy (Lewis-Sumner syndrome) and motor neuron disease (MND).

Although MMN has meanwhile been identified as a distinct nosological entity and significant success has

Christoph Kleinschnitz, MD

Department of Neurology, University of Wuerzburg

Josef-Schneider-Strasse 11, DE-97080 Wuerzburg (Germany)

Tel. +49 9312012 3765, Fax +49 93120123488

E-Mail christoph.kleinschnitz@mail.uni-wuerzburg.de 
been made in elucidating important aspects of the disease, several issues remain to be clarified. For example, there are still unsettled questions concerning the etiology of MMN, the biological basis of CBs as well as the optimum long-term therapy $[8,19-21]$.

\section{Clinical Features and Disease Course}

MMN is a rare disease with an estimated prevalence of $1-2 / 100,000$ individuals. It is more frequent in men than women, with an approximate ratio of 3:1. The mean age at disease onset is 40 years. Almost $80 \%$ of the patients develop first symptoms between 20 and 50 years of age $[7,9]$. Thus, MMN predominantly affects young people. Clinically, MMN is characterized by slowly progressive or stepwise progressive, asymmetric and distally accentuated paresis related to distinct peripheral nerves. The upper limbs are usually affected earlier and more severe than the lower limbs $[6,7,22,23]$. In only $5-10 \%$ of all cases MMN manifests with proximal muscle weakness $[9,24]$. The most common initial symptom is wrist drop and impaired grip strength. Muscle atrophy is often mild in the early stage, but may become prominent during the course of the disease when it is usually associated with a poor response to immunomodulatory therapy [13, 25]. Other symptoms comprise fasciculations and muscle cramps in about $50 \%$ of the patients, while myokymia has only been reported occasionally $[1,25]$. Another characteristic that defines $\mathrm{MMN}$ is the absence of sensory symptoms. Only a few patients complain of discrete paresthesia or numbness during the course of the disease, and a minor loss of vibration sense has been documented in $20 \%$ of the subjects $[7,9]$. Tendon reflexes from the paretic muscles are usually reduced but may be normal or even, though rarely, brisk. In the latter case, differentiation from amyotrophic lateral sclerosis or lower motorneuron disease can be difficult. Cranial nerve involvement is uncommon and, if present, predominantly affects the N. Hypoglossus [26, 27].

Most patients develop a slowly progressive disease course in which the degree of disability correlates with the overall duration of the disease $[28,29]$. Besides, relapsing forms of MMN showing acute deterioration, stepwise progression, as well as spontaneous remissions have occasionally been described $[2,13,30]$. Anecdotic reports on subacute monophasic MMN presenting with tetraparesis, preserved tendon reflexes and normal motor and sensory nerve conduction following Campylobacter jejuni infections [31-33] most likely reflected aberrant forms of Guillain-Barré syndrome (GBS) [34]. Although the prognosis ad vitam is favorable and only 2 fatal cases have been directly ascribed to MMN after several years of disease $[3,27]$, the majority of patients accumulate significant disability as a result of severe paresis. Moreover, pathological fatigue was only recently highlighted in MMN [28, 35, 36].

\section{Pathophysiology of MMN}

\section{Molecular Basis of Conduction Block}

The electrophysiological hallmarks of MMN are CBs (see 'Electrophysiological Findings' below) which are supposed to be the underlying cause of muscle weakness. However, patients exist who present with clinical symptoms typical for MMN but in whom CBs cannot be detected by routine neurography. Here, very proximal or distal CBs inaccessible to standard neurography might be present [16]. Interestingly, the majority of nerve-conduction studies in MMN demonstrated significant improvement of CBs after treatment with IVIgs, although muscle strength in these patients rarely recovers to normal [10].

In general, $\mathrm{CB}$ appears when the incoming action current at the node of Ranvier is unable to induce sufficient depolarization at the subsequent node to generate an action potential $[37,38]$. Experimental paranodal demyelination in rodents severely impaired saltatoric nerve conduction suggesting that focal demyelination is the pathological basis of CB $[23,39]$. This hypothesis was further strengthened by morphological nerve studies confirming circumscribed demyelination in biopsies from MMN patients [38-41]. Beyond focal demyelination, generalized axonal dysfunction might be present in MMN [42]. Pathological and electrophysiological findings have highlighted the functional role of axonal disintegration and impaired axon-myelin interactions [41, 4346]. The question whether axonal degeneration is an intrinsic pathophysiological feature of $\mathrm{MMN}$ or caused by persistent CBs is still under debate. Recent studies point out that activity-dependent processes can induce $\mathrm{CB}$-induced axonal degeneration. According to this, the axonal membrane hyperpolarizes at the vicinity of a $\mathrm{CB}$ due to altered $\mathrm{K}^{+}$conductivity [42], but depolarizes at the site of $\mathrm{CB}$ through inhibition of the $\mathrm{Na}^{+} / \mathrm{K}^{+}$-ATPase caused e.g. by edema, reduced oxygen supply or immune-mediated mechanisms such as binding of autoantibodies [38, 46] (fig. 1A, B). This scenario is further aggravated by disruption of the blood-nerve barrier leading to increased $\mathrm{K}^{+}$ concentrations in the endoneural fluid hence further 


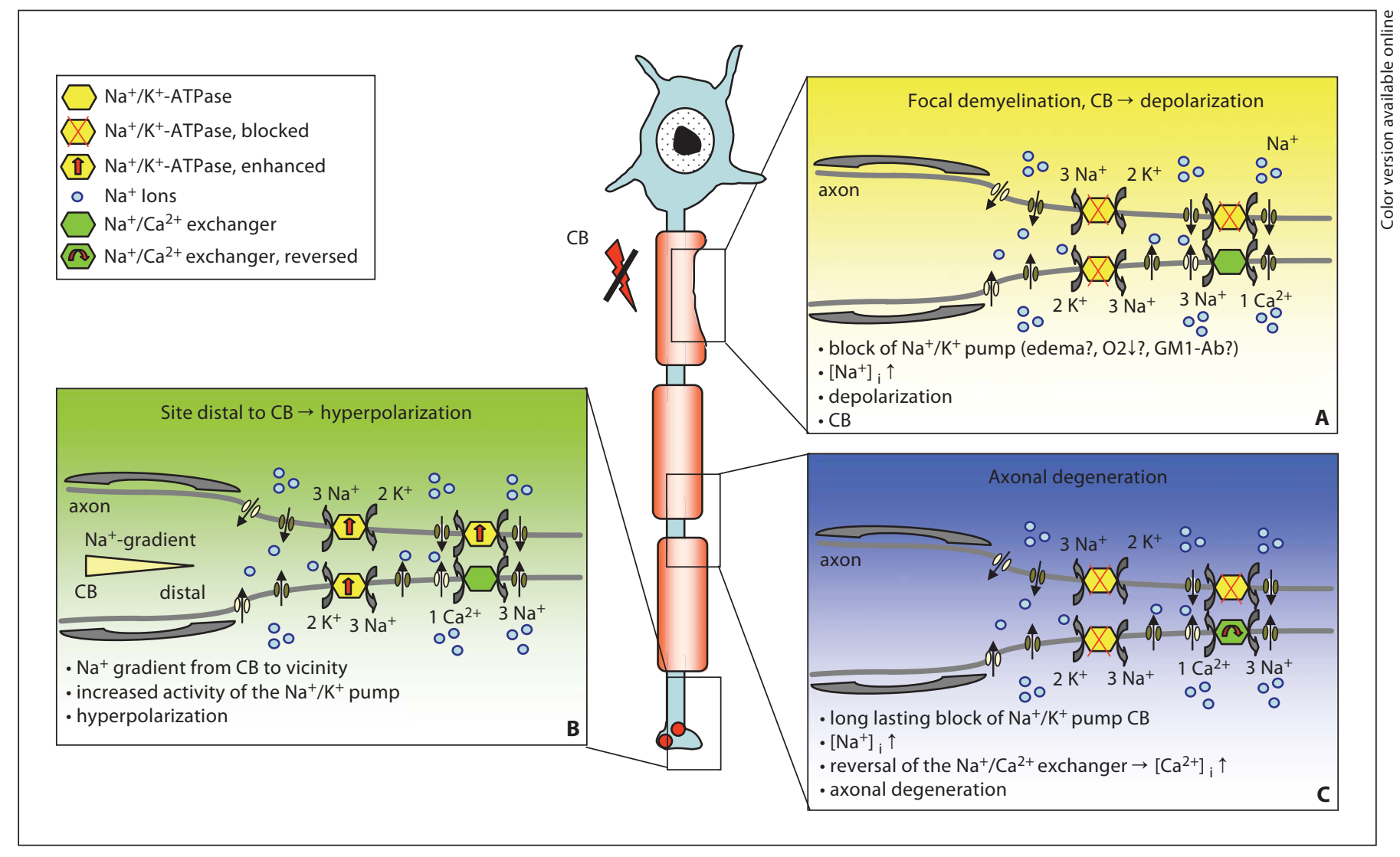

Fig. 1. Possible molecular mechanisms of $\mathrm{CB}$ and axonal degeneration in MMN. A Edema formation, restricted $\mathrm{O}_{2}$ diffusion and/ or antibody-mediated processes following focal demyelination can cause inhibition of $\mathrm{Na}^{+} / \mathrm{K}^{+}$pumps. This then leads to an increase in intracellular $\mathrm{Na}^{+}$and, according to the electrogenic nature of the $\mathrm{Na}^{+} / \mathrm{K}^{+}$-ATPase, to depolarization of the membrane potential. Significant depolarization finally presents as CB. B Lo- cally increased $\mathrm{Na}^{+}$concentrations at the site of $\mathrm{CB}$ form a $\mathrm{Na}^{+}$ gradient at the vicinity of $\mathrm{CB}$. This scenario activates $\mathrm{Na}^{+} / \mathrm{K}^{+}$ pumps (increased 'driving force') accompanied by membrane hyperpolarization. C Persistent $\mathrm{CB}$ can saturate the activity of the sodium-transporting machinery, hence reversing the function of the $\mathrm{Na}^{+} / \mathrm{Ca}^{2+}$ exchanger. As a consequence, $\mathrm{Ca}^{2+}$ accumulates in the axon and finally causes axonal degeneration. supporting accumulation of intracellular $\mathrm{Na}^{+}$ions and membrane depolarization. Persistent $\mathrm{Na}^{+}$influx can only be counterbalanced by $\mathrm{Na}^{+}$ions moving intracellularly along the axon to a site where the $\mathrm{Na}^{+} / \mathrm{K}^{+}$pump is still functional. As a consequence, the $\mathrm{Na}^{+}$gradient from the lesion site to the distal part of the nerve is decreased [46] (fig. 1B). Raised intracellular $\mathrm{Na}^{+}$concentrations are the 'driving force' for the $\mathrm{Na}^{+} / \mathrm{K}^{+}$-ATPase resulting in increased pump activity and membrane hyperpolarization [47-49]. According to this pathophysiological concept, ongoing $\mathrm{CB}$ would trigger sustained elevation in intracellular $\mathrm{Na}^{+}$. Under these conditions the activity of the $\mathrm{Na}^{+} /$ $\mathrm{Ca}^{2+}$ exchanger $\left(3 \mathrm{Na}^{+} / 1 \mathrm{Ca}^{2+}\right)$ can be reversed [44-46, 50] leading to intra-axonal accumulation of $\mathrm{Ca}^{2+}$ and subsequent axonal degeneration (fig. 1C).

\section{Immunopathogenesis of MMN}

There are several arguments for MMN being an immune-mediated disease [5, 6, 25]: anti-GM1 antibodies are found in $20-80 \%$ of patients suffering from MMN, and GM1 is expressed on axons and the myelin sheath. Interestingly, the molecular composition of GM1 differs between sensory and motor nerves resulting in different binding affinities of anti-GM1 antibodies hence, offering a possible explanation for the selective impairment of motor fibers in MMN [51-53]. Moreover, many MMN patients respond to immunomodulatory treatment. Finally, highly specific therapies that selectively interfere with the immune system such as TNF $\alpha$ antagonists (infliximab) can induce MMN in rare cases [54]. Similar to other neurological disorders associated with serum anti- 
bodies the question arises whether anti-GM1 antibodies in MMN are pathologically relevant or represent a mere epiphenomenon. Indeed, previous studies reported antiGM1-mediated focal demyelination and blockade of voltage-dependent $\mathrm{Na}^{+}$channels at the node of Ranvier in vivo and in vitro [55-57], but these findings could not be confirmed by others [58-60]. Although human IgM antiGM1 antibodies can act on voltage-gated $\mathrm{Ca}^{2+}$ channels in vitro, the significance of this interaction for the pathogenesis of MMN remains unclear [61]. The remarkable proportion of anti-GM1 antibody-negative patients (up to $50 \%$ ) who, in comparison to anti-GM1-positive individuals, similarly respond to IVIg argues against an exclusively antibody-mediated disease mechanism $[12,25$, $62,63]$. Along these lines motor-nerve conduction in mice could be blocked by human serum samples devoid of anti-GM1 antibodies indicating that other soluble mediators are pathogenetically relevant in $\mathrm{MMN}[10,64]$. Finally, IVIg treatment, although clinically effective, does not reduce anti-GM1 titers $[4,65]$.

Taken together, the exact immune mechanisms operative during MMN are still unknown and the available data can currently not prove or disprove a causative pathogenetic role of anti-GM1 antibodies [64].

\section{Diagnostics of MMN}

\section{Electrophysiological Findings}

The most prominent electrophysiological features in MMN are multifocal, persistent, partial CBs present in motor but not sensory nerve fibers and located outside the common entrapment sites [3, 12, 66, 67] (see 'Molecular Basis of Conduction Block' above). In general, CB has been defined as the reduction of the amplitude or area under the curve of the compound motor action potential (CMAP) on proximal compared to distal nerve stimulation. However, consensus on the required magnitude of amplitude or area reduction that unambiguously defines partial CB has not yet been reached. This is mainly due to the fact that besides $\mathrm{CB}$, several other mechanisms can lead to significant CMAP reduction ('pseudo CB'). Because axons of a chronically demyelinated nerve display different conduction velocities (known as temporal dispersion, TD), the positive phase of the fast motor-unit action potentials overlaps with the negative phase of slow motor-unit action potentials (a phenomenon called 'interphase cancellation'), resulting in a disproportionate proximal CMAP that can mimic true CB [68-71]. TD is common in chronic demyelinating disorders of the pe- ripheral nervous system, such as CIDP or polyneuropathy associated with IgM gammopathy. In addition, collateral nerve sprouting present for example in MND increases the rate of polyphasia and reduces CMAP amplitudes $[72,73]$. Finally, technical limitations such as insufficient supramaximal stimulation of the proximal nerve segments can lead to pseudo-CB.

The degree of CMAP reduction necessary to define partial CB in MMN varies considerably between different studies, ranging from $20 \%$ to more than $50 \%$ with a maximum admissible TD between 15 and 30\% [7, 9]. A computer simulation study in rats, in which compound muscle-unit action potentials were reconstructed from motor-unit action potentials, showed that maximum TD can result in a decrement in the CMAP area of up to $50 \%$ [70]. A recent retrospective investigation in humans for the first time established simulation-based thresholds for $\mathrm{CB}$ in the forearm segment of the median nerve [23]. However, these thresholds still have to be evaluated for other nerves and validated in a prospective manner. Even in healthy individuals CMAP amplitudes are commonly lower after proximal compared to distal nerve stimulation with a range of reduction between 12 and 54\% [74]. Given the results from the above-referenced studies, the commonly applied cutoff level of 50\% CMAP decline (amplitude or area) is the most validated electrophysiological criterion of partial CB. Consequently, this threshold was chosen for the definition of definite partial CB in most of the peripheral nerves according to the consensus criteria of the American Association of Electrodiagnostic Medicine [18] and the European Federation of Neurological Societies/Peripheral Nerve Society (table 1). However, the 50\% limit should not be applied if CMAP amplitudes are below $20 \%$ of the normal value. Then, potentials are often too polyphasic to allow proper quantification. The relatively restrictive American und European electrophysiological criteria aim to avoid confusion between real CB and TD, i.e. pseudo-CB. This approach, however, may lead to the underdiagnosis of $M M N$ which represents a potentially treatable neuropathy $[28,67,71$, $75,76]$. Hence, it is important to bear in mind that a reduction in amplitude or area smaller than 50\% might already represent partial $\mathrm{CB}$, especially because $\mathrm{CB}$, although considered to be persistent $[73,77]$, is a dynamic entity that changes over time [75], and a CMAP reduction of $>50 \%$ may be preceded by a smaller decrease underlining the need for electrophysiological evaluation at regular intervals. Sometimes subtle focal CB can be detected using the so-called 'inching technique' where several nerve sites with an interstimulation distance of $10-15 \mathrm{~mm}$ are 
stimulated sequentially $[78,79]$. Here, an abrupt and circumscribed reduction in CMAP amplitude differentiates focal CB from pseudo-CB which, in contrast, is characterized by a more gradual CMAP decrease with increasing stimulation distances. At the site of $\mathrm{CB}$, conduction velocity in motor but not sensory fibers is usually significantly reduced. Moreover, one should bear in mind that the same nerve can be blocked at several sites $[12,67$, 80].

It is important to note that $\mathrm{CB}$ is not specific for MMN but can also be found in several other neuropathies. In contrast to $\mathrm{MMN}, \mathrm{CB}$ occurring during acute compressive neuropathy or hereditary neuropathy with liability to pressure palsies are located at common anatomical entrapment sites like the ulnar sulcus or caput fibulae while those present after ischemic nerve injury are transient and usually reversible [81, 82]. Patients suffering from GBS or CIDP in addition to CB regularly develop other electrophysiological signs of severe demyelination like markedly prolonged distal motor latencies or increased F-wave latencies [83, 84].

Another specific problem with the diagnosis of MMN is the detection of proximally located CB. Due to anatomical restrictions, the routinely used surface electrodes are not able to stimulate proximal nerve segments (plexus, nerve roots). This technical limitation can be overcome by the application of transcutaneous magnetic coils or high voltage stimulators $[85,86]$ which, however, can often not deliver the focal impulses necessary for the exact calculation of nerve conduction velocities or are inappropriate for supramaximal fiber stimulation [87]. Although $\mathrm{F}$ waves provide information on the integrity of a peripheral nerve over its whole course and, at least theoretically, should be an ideal tool for the detection of (proximal) CB, F-wave persistency depends on several other factors such as axonal integrity and its reduction does not necessarily indicate proximal CB [86]. Whether the recently reported 'magnetic fatigue test' in which activitydependent $\mathrm{CBs}$ are unmasked by serial magnetic stimulation [88] can indeed delineate between true $\mathrm{CB}$ and the reduction of CMAP in MND needs to be further established. Finally, a novel approach using a triple stimulation technique to detect $\mathrm{CB}$ proximal to Erb's point might help to increase the diagnostic sensitivity in the future [89].

Although CB clearly is an important hallmark of $M M N$, the question whether its presence is mandatory for the diagnosis of MMN is still under debate [90]. About 30 cases of MMN with typical clinical presentation and a good response to IVIg but without CB have been reported so far $[4,76,91,92]$. In a recent retrospective anal-
Table 1. Electrophysiological criteria of definite $\mathrm{CB}$ according to the EFNS/PNS Joint Task Force [115] and the AAEM [87]

\begin{tabular}{lll}
\hline Nerve segment & $\begin{array}{l}\text { Amplitude } \\
\text { reduction }{ }^{\text {a }} \%\end{array}$ & $\begin{array}{l}\text { Area } \\
\text { reduction, \% }\end{array}$ \\
\hline $\begin{array}{ll}\text { Median nerve } \\
\quad \text { Elbow/wrist }\end{array}$ & $>50$ & $>40(50)$ \\
$\quad$ Axilla/elbow & $>50$ & $>40(50)$ \\
$\begin{array}{l}\text { Ulnar nerve } \\
\text { Elbow/wrist }\end{array}$ & $>50$ & $>40(50)$ \\
$\quad$ Elbow prox./dist. & $>50$ & $>40(50)$ \\
$\quad$ Axilla/prox. elbow & $>50$ & $>40(50)$ \\
$\begin{array}{l}\text { Peroneal nerve } \\
\quad \text { Dist. fibula/ankle }\end{array}$ & $>60$ & $>50(50)$ \\
$\quad$ Fibula prox./dist. & $>50$ & $>40(50)$ \\
$\begin{array}{l}\text { Tibial nerve } \\
\text { Knee/ankle }\end{array}$ & $>60$ & $>50$ \\
\hline
\end{tabular}

Values in brackets according to the EFNS/PNS Joint Task Force [115].

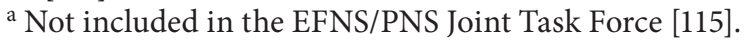

ysis, patients with and without CB showed similar clinical features and a comparable response to IVIg treatment after a median follow-up of 7 years, suggesting related, if not identical disease entities [93]. Final appraisal of the existence of CB-negative $\mathrm{MMN}$ is hampered in that it is not clear whether these subjects really never had $\mathrm{CB}$ or whether CB merely disappeared over time due to secondary axonal degeneration and subsequent reduction also of the distal CMAP amplitudes [22, 28, 94].

Other electrophysiological hallmarks in MMN apart from $\mathrm{CB}$ can comprise increased distal CMAP latencies and prolonged or absent F-waves both of which mainly result from mild demyelination [13, 67, 80, 95]. The clinical finding of severely paretic muscles but with preserved bulks and normal neurography from the corresponding nerves is suspicious for distally located CBs. Those can occasionally be confirmed by needle electromyography $(E M G)$ when an increased motor unit discharge rate $(>20$ $\mathrm{Hz})$ in the absence of spontaneous activity is found [74].

\section{Laboratory Findings}

The most common laboratory findings in MMN are IgM serum antibodies against the ganglioside GM1 [4] which can be detected at high titers in $30-80 \%$ of the patients $[7,9]$. The reported variations in the incidence of GM1 antibodies are probably related to the different ELISA assays used in the different studies as well as heterogeneous control populations [27, 96-99]. Besides 
GM1 antibodies, immunoreactivity against other axon or myelin components such as the glycolipids GDla or GM2 can be infrequently found $[80,100,101]$. The applicability of anti-GM2 antibodies for diagnosing MMN has recently been confirmed in a retrospective study including patients with different neuropathies [44]. Because glycolipids are presented to antigen-specific T cells by $\mathrm{CD} 1$ molecules expressed on the surface of various antigen-presenting cells, a possible association of MMN and other chronic immune-mediated neuropathies with gene polymorphisms coding for CD1A and CD1E was hypothesized but could not be confirmed [45]. Similar to $\mathrm{CB}$, anti-GM1 antibodies are not specific for MMN. They also occur in 5-10\% of patients with MND, other immune-mediated neuropathies (GBS, CIDP) and even in healthy individuals [102-105], although GM1 titers are usually lower under these conditions compared to MMN [22, 106]. Interestingly, anti-GM1-antibodies of the IgG subclass are frequently found at high concentrations in patients with MADSAM neuropathy [107], GBS and MND [99]. Taken together, the detection of antiGM1-IgM antibodies supports the diagnosis of MMN, while a negative finding does not exclude the disease.

Most routine laboratory parameters in MMN are normal. Muscle creatine kinase is supposed to be slightly elevated in about two thirds of the patients $[28,95]$. However, this unspecific finding does not help to differentiate MMN from MND or other neuropathies. This is also true for analysis of the cerebrospinal fluid which, in most cases, shows a discrete increase in overall protein concentration (up to $80 \mathrm{mg} / \mathrm{dl}$ ) but normal cell counts [108]. Serum electrophoresis might reveal elevated polyclonal antibody formation, while monoclonal peaks typical for IgM gammopathy are generally absent $[4,109]$.

\section{Nerve Biopsy}

Biopsies taken from sensory nerves (e.g. sural nerve) are naturally not helpful for the diagnosis of $\mathrm{MMN}$ and should only be performed if significant sensible deficits are present, and CIDP, Lewis-Sumner syndrome or vasculitis have to be taken into account. Accordingly, only a few reports on sensory nerve biopsies in MMN exist and those described either normal findings or unspecific signs of mild axonal degeneration, demyelination, or both, consistent with the infrequent sensory impairment in patients with $\mathrm{MMN}[79,110]$. Tissue samples taken from the motor nerves of MMN patients are likewise rare. Auer et al. [40] reported thinly myelinated axons and the formation of onion bulbs at the site of the suspected $\mathrm{CB}$, which typically indicate simultaneous de-and
Table 2. Diagnostic criteria of MMN according to EFNS/PNS Joint task force [115] and AAEM [87]

Essential criteria for the diagnosis of definite MMN

1 Slowly progressive or stepwise progressive asymmetric limb weakness related to at least two distinct peripheral nerves for more than 1 month (usually more than 6 months)

2 No objective sensory deficits except for minor vibration sense abnormalities in the lower limbs

3 Definite CB (table 1) in two or more peripheral motor nerves outside the common entrapment sites

4 Normal neurography from at least three peripheral sensory nerves

5 Absence of upper motor neuron sings (spasticity, cloni, bulbar symptoms, pyramidal tract signs)

Supportive criteria according to EFNS/PNS Joint Task Force [115]

1 Predominant upper limb involvement at onset

2 Decreased or absent tendon reflexes in the affected limb

3 Absence of cranial nerve involvement

4 Cramps and fasciculations in the affected limb

5 Elevated IgM anti-ganglioside GM1 antibodies

6 MRI showing gadolinium enhancement and/or hypertrophy of the brachial plexus

7 Clinical improvement following IVIg treatment

Exclusion criteria

Upper motor neuron signs

Marked bulbar involvement

Significant sensory impairment

4 Diffuse or symmetric pattern of paresis at the beginning of the disease

$5 \quad$ CSF protein $>1 \mathrm{~g} / \mathrm{l}$

remyelination. In another study axonal degeneration outweighed myelin pathology, and onion bulb formation as well as para- and internodal demyelination were absent [111]. In contrast to CIDP, inflammatory cells invading the nerve are only sporadically found in MMN underlining that different disease mechanisms are functional $[40,43,111]$.

\section{Magnetic Resonance Imaging}

About $40-50 \%$ of the patients with MMN show hyperintense signals on T2-weighted magnetic resonance imaging (MRI) or contrast-enhanced T1 sequences of the brachial plexus [112]. The pattern of signal alterations closely correlates with the distribution of muscle weakness $[23,28,43,112]$ and might colocalize with CB [43, 113]. Although these findings are unspecific and do not unravel the underlying pathology except for demonstrating edema and an impaired blood-nerve barrier, MRI 
Table 3. Important differential diagnoses of $\mathrm{MMN}$

\begin{tabular}{|c|c|c|c|c|}
\hline & MMN & MND & CIDP & MADSAM neuropathy \\
\hline Symptom pattern & Asymmetrical & Asymmetrical & Symmetrical & Asymmetrical \\
\hline Sensory symptoms & No & No & Yes & Yes + pain \\
\hline Tendon reflexes & Decreased & Increased & Areflexia & Decreased \\
\hline Disease course & Slowly progressive & Rapidly progressive & Progressive/relapsing & Progressive/relapsing \\
\hline CSF protein & $<1 \mathrm{~g} / \mathrm{l}$ & $<1 \mathrm{~g} / 1$ & $>1 \mathrm{~g} / 1$ & Rarely > 1 g/l \\
\hline IgM anti-GM1 antibodies & $\sim 30-50 \%$ & $\sim 10 \%$ & Rare & No \\
\hline Response to IVIg & Yes & No & Yes & Yes \\
\hline Response to steroids & No (worsening) & No & Yes & Yes \\
\hline
\end{tabular}

could become an elegant and noninvasive tool to assess the integrity of proximal nerve segments in the future. Since the pathological MRI signals in MMN are mainly asymmetrically distributed, this technique might in addition help to delineate MMN from similar entities such as CIDP in which signal alterations are usually symmetrical or MND showing normal MRI of the peripheral nervous system $[112,114]$.

\section{Diagnostic Criteria and Differential Diagnosis}

Several diagnostic criteria for MMN have been proposed since the first description of the disease $[18,28,110$, 115]. Most of them share similar features and are based on the characteristic clinical and electrophysiological findings. According to the American Association of Electrodiagnostic Medicine and the European Federation of Neurological Societies/Peripheral Nerve Society definite MMN requires slowly progressive or stepwise progressive asymmetric paresis related to two or more distinct peripheral nerves without objective sensory deficits (table 2). Clinical findings that exclude the diagnosis of MMN comprise upper motor neuron signs like spasticity, extensor plantar responses and bulbar palsy. Electrophysiological requirements are met if definite $C B$ is detected within at least two different nerves outside the preformed entrapment sites.

The most relevant differential diagnoses are summarized in table 3. In contrast to MND, MMN is characterized by its mononeuritis multiplex-like distribution of muscle weakness, which is not simply asymmetric but follows distinct peripheral nerves [2, 116-118]. Furthermore, the disease course in $\mathrm{MMN}$ is more protracted and bulbar symptoms are missing. Finally, severe muscle atrophy is less common in MMN at least during early stag- es. In line with this, spontaneous activity in EMG is more pronounced and widespread in MND including, e.g. paraspinal muscle groups. However, discrimination between MMN and 'lower motor neuron disease' presenting without upper motor neuron signs is often difficult on a mere clinical basis. Here, detection of $\mathrm{CB}$ and the presence of anti-GM1 antibodies can be helpful. Patients suffering from chronic polyneuritis predominantly develop sensory symptoms and symmetric muscle weakness which is accompanied by reduced or absent tendon reflexes. Electrophysiological findings are characterized by significant demyelination of both, motor and sensory nerves and the symptoms are often relapsing-remitting $[19,25,119]$. The distinction of MMN from Lewis-Sumner syndrome (MADSAM neuropathy) $[77,120]$ often appears a difficult challenge. MADSAM neuropathy is also a multifocal neuropathy with $\mathrm{CB}$ but, in contrast to MMN, significantly involves the sensory system and is often associated with neuropathic pain. Unfortunately, the extent of sensory deficits still consistent with MMN is not exactly defined $[17,18]$. Therefore, the detection of reduced potentials in different sensory nerves by neurography is the most valid criterion that separates MADSAM from MMN. In addition, anti-GM1 antibodies are absent and cerebrospinal fluid protein is often elevated in LewisSumner syndrome $[118,121]$. Making the correct differential diagnosis is of more than academic interest because some patients with Lewis-Sumner syndrome respond to steroids, which are ineffective or even harmful in MMN patients (see below) $[121,122]$. Whether it is really of clinical relevance to further separate pure MMN from $\mathrm{MMN}$ with sensory loss and MADSAM neuropathy clearly needs further evaluation [123]. Finally, acquired or hereditary entrapment neuropathies, e.g. hereditary neuropathy with liability to pressure palsies, should be taken into account [124]. These are often characterized by acute 
and painful onset, and nerve damage is restricted to preformed anatomical entrapment sites (e.g. sulcus ulnaris, carpal tunnel).

\section{Therapy}

Because MMN is supposed to be an immune-mediated disease, various immunomodulatory treatment strategies have been applied to date in MMN patients. In contrast to CIDP and Lewis-Sumner syndrome, numerous studies have demonstrated that glucocorticosteroids and plasma exchange are ineffective in MMN. In fact, they even worsen the symptoms in up to $20 \%$ of MMN patients, underlining that different pathophysiological mechanisms must be functional $[3,4,16,85,125,126]$. Nowadays, IVIgs are regarded as first-line therapy and their efficacy in MMN has meanwhile been proven in 4 large double-blind, placebo-controlled trials $[17,23,63$, 127-129]. In addition, 2 retrospective trials confirmed that IVIg is initially effective in $70-86 \%$ of the patients by most individuals require periodic treatment for several years $[130,131]$. Whether the subcutaneous route of IVIg administration is advantageous compared to regular intravenous infusions with respect to steady IVIg plasma concentrations, patients' quality of life or cost-effectiveness needs further evaluation [132-134]. Similar to other neurological disorders, the exact mechanism of action of IVIg in MMN is still unclear at present [135]. This also applies for the question whether patients with high titers of anti-GM1 antibodies respond better to IVIg compared to those with lower titers $[7,25,95]$. The clinical effect of IVIg is usually impressive and muscle strength improves substantially within the first week of treatment. Otherwise, the diagnosis should be reconsidered, although chronic paresis and muscle atrophy do not recover after IVIg application in most of the cases. While anti-GM1 antibody titers are not affected by IVIg and thus, are not suitable as therapeutic markers, disappearance of partial CB sometimes parallels clinical improvement [136-138]. The common IVIg dose at the beginning of the disease is $2 \mathrm{~g} / \mathrm{kg}$ body weight given on $2-5$ consecutive days. However, the treatment effect usually rapidly declines after several weeks. Therefore, it is important to find an applicable maintenance regime with individualized IVIg doses (e.g. $0.4 \mathrm{~g} / \mathrm{kg}$ IVIg once weekly or $1-2 \mathrm{~g} / \mathrm{kg}$ IVIg in monthly intervals) in order to optimize the cost-to-benefit ratio $[62,139]$. Nevertheless the efficacy of IVIg decreases after several years of treatment in most of the patients, necessitating higher dosage or shortened infusion intervals to stabilize the symptoms $[94,140]$. The recent observation that higher doses of IVIg might be superior already at the initial stage [141] and be able to prevent secondary axonal degeneration or promote remyelination [142] needs to be confirmed in larger studies and valid data on the long-term efficacy of IVIg in MMN are missing.

Soon after the initial description of MMN, cyclophosphamide was tested for this indication in several small uncontrolled trials. Taken together, high doses of cyclophosphamide seem to have a moderate effect, especially when given intravenously while lower oral doses could not influence disease progression [4, 12, 26, 143]. Brannagan et al. [144] recently reported a patient with refractory MMN who experienced sustained disease remission after high-dose cyclophosphamide $(50 \mathrm{mg} / \mathrm{kg}$ body weight over 4 days) without stem cell rescue. In contrast, myeloablative cyclophosphamide followed by autologous stem cell transplantation worsened the symptoms in another patient [145]. Hence, further studies are clearly needed to finally judge the therapeutic potential of aggressive immunosuppressive regimens in MMN. Given its problematic risk-to-benefit ratio, cyclophosphamide is currently only recommended if IVIg is not sufficiently effective [17].

Many other immunomodulatory or immunosuppressive agents such as azathioprine, methotrexate, cyclosporin $\mathrm{A}$, mycophenolate mofetil or $\beta$-interferons have occasionally been tested in MMN but in most cases revealed conflicting results and controlled trials on these substances are missing [3, 146-149]. Data concerning the efficacy of the monoclonal antibody rituximab, which targets the CD20 molecule on B cells and might be able to reduce pathological autoantibody levels in $\mathrm{MMN}$, are likewise inconclusive and larger trials are needed [150152].

\section{Conclusion}

During the past 20 years numerous clinical and electrophysiological studies have helped to shed light on the pathophysiology of MMN and led to significant advances in its diagnosis and treatment. IVIg can restore muscle strength and delay disease progression. However, therapies with proven long-term efficacy or even strategies able to cure the disease are still lacking underlining the need to continue the search for innovative treatment approaches. Although MMN is typically characterized by $\mathrm{CB}$ most likely caused by focal demyelination, the patho- 
physiological abnormalities probably extend far beyond. Novel morphological and electrophysiological findings highlight the importance of axonal degeneration and impaired axon-myelin interactions, which probably occur already at early stages of MMN. Finally, anti-GM1 anti- bodies seem to represent a valid diagnostic marker rather than the true trigger of the disease and other possible targets of the immune response in MMN await identification.

\section{References}

-1 Roth G, Rohr J, Magistris MR, Ochsner F: Motor neuropathy with proximal multifocal persistent conduction block, fasciculations and myokymia. Evolution to tetraplegia. Eur Neurol 1986;25:416-423.

2 Chad DA, Hammer K, Sargent J: Slow resolution of multifocal weakness and fasciculation: a reversible motor neuron syndrome. Neurology 1986;36:1260-1263.

\3 Parry GJ, Clarke S: Multifocal acquired demyelinating neuropathy masquerading as motor neuron disease. Muscle Nerve 1988; 11:103-107.

4 Pestronk A, Cornblath DR, Ilyas AA, Baba H, Quarles RH, Griffin JW, Alderson K, Adams RN: A treatable multifocal motor neuropathy with antibodies to GM1 ganglioside. Ann Neurol 1988;24:73-78.

5 Kornberg AJ, Pestronk A: The clinical and diagnostic role of anti-GM1 antibody testing. Muscle Nerve 1994;17:100-104.

-6 Biessels GJ, Franssen H, van den Berg LH, Gibson A, Kappelle LJ, Venables GS, Wokke JH: Multifocal motor neuropathy. J Neurol 1997;244:143-152.

7 Nobile-Orazio E: Multifocal motor neuropathy. J Neuroimmunol 2001;115:4-18.

$>8$ Leger JM, Behin A: Multifocal motor neuropathy. Curr Opin Neurol 2005;18:567573.

$\checkmark 9$ Nobile-Orazio E, Cappellari A, Priori A: Multifocal motor neuropathy: current concepts and controversies. Muscle Nerve 2005; 31:663-680.

10 Van Asseldonk JT, Franssen H, Van den Berg-Vos RM, Wokke JH, Van den Berg LH: Multifocal motor neuropathy. Lancet Neurol 2005;4:309-319.

-11 Charles N, Benoit P, VialC, Bierme T, Moreau $\mathrm{T}$, Bady B: Intravenous immunoglobulin treatment in multifocal motor neuropathy. Lancet 1992;340:182.

-12 Chaudhry V, Corse AM, Cornblath DR, Kuncl RW, Drachman DB, Freimer ML, Miller RG, Griffin JW: Multifocal motor neuropathy: response to human immune globulin. Ann Neurol 1993;33:237-242.

-13 Nobile-Orazio E, Meucci N, Barbieri S, Carpo M, Scarlato G: High-dose intravenous immunoglobulin therapy in multifocal motor neuropathy. Neurology 1993;43:537544
14 Umapathi T, Hughes RA, Nobile-Orazio E, Léger JM: Immunosuppressive treatment for multifocal motor neuropathy. Cochrane Database Syst Rev 2002;2:CD003217.

15 Umapathi T, Hughes RA, Nobile-Orazio E, Léger JM: Immunosuppressant and immunomodulatory treatments for multifocal motor neuropathy. Cochrane Database Syst Rev 2005;3:CD003217.

16 Nobile-Orazio E: What's new in multifocal motor neuropathy in 2007-2008? J Peripher Nerv Syst 2008;13:261-263.

17 van Schaik IN, Bouche P, Illa I, Leger JM, Van den Bergh P, Cornblath DR, Evers EM, Hadden RD, Hughes RA, Koski CL, NobileOrazio E, Pollard J, Sommer C, van Doorn PA: European Federation of Neurological Societies/Peripheral Nerve Society guideline on management of multifocal motor neuropathy. Eur J Neurol 2006;13:802-808.

18 Olney RK, Lewis RA, Putnam TD, Campellone JV Jr: Consensus criteria for the diagnosis of multifocal motor neuropathy. Muscle Nerve 2003;27:117-121.

19 Saperstein DS, Amato AA, Barohn RJ: Clinical and genetic aspects of distal myopathies. Muscle Nerve 2001;24:1440-1450.

20 Van Doorn PA, Garssen MP: Treatment of immune neuropathies. Curr Opin Neurol 2002;15:623-631.

21 Kieseier BC, Kiefer R, Gold R, Hemmer B, Willison HJ, Hartung HP: Advances in understanding and treatment of immune-mediated disorders of the peripheral nervous system. Muscle Nerve 2004;30:131-156.

22 Taylor BV, Wright RA, Harper CM, Dyck PJ: Natural history of 46 patients with multifocal motor neuropathy with conduction block. Muscle Nerve 2000;23:900-908.

23 Van Asseldonk JT, Van den Berg LH, Van den Berg-Vos RM, Wieneke GH, Wokke JH, Franssen H: Demyelination and axonal loss in multifocal motor neuropathy: distribution and relation to weakness. Brain 2003; 126:186-198.

24 Maurer M, Stoll G, Toyka KV: Multifocal motor neuropathy presenting as chronic progressive proximal leg weakness. Neuromuscul Disord 2004;14:380-382.

25 Bouche P, Moulonguet A, Younes-Chennoufi AB, Adams D, Baumann N, Meininger V, Leger JM, Said G: Multifocal motor neuropathy with conduction block: a study of 24 patients. J Neurol Neurosurg Psychiatry 1995; 59:38-44.
26 Kaji R, Shibasaki H, Kimura J: Multifocal demyelinating motor neuropathy: cranial nerve involvement and immunoglobulin therapy. Neurology 1992;42:506-509.

27 Magistris M, Roth G: Motor neuropathy with multifocal persistent conduction blocks. Muscle Nerve 1992;15:1056-1057.

28 Van den Berg-Vos RM, Franssen H, Wokke JH, Van Es HW, Van den Berg LH: Multifocal motor neuropathy: diagnostic criteria that predict the response to immunoglobulin treatment. Ann Neurol 2000;48:919926.

29 Terenghi F, Allaria S, Nobile-Orazio E: Circulating levels of cytokines and their modulation by intravenous immunoglobulin in multifocal motor neuropathy. J Peripher Nerv Syst 2006;11:67-71.

30 O'Leary CP, Mann AC, Lough J, Willison HJ: Muscle hypertrophy in multifocal motor neuropathy is associated with continuous motor unit activity. Muscle Nerve 1997;20: 479-485

31 White JR, Sachs GM, Gilchrist JM: Multifocal motor neuropathy with conduction block and Campylobacter jejuni. Neurology 1996; 46:562-563.

32 Abbruzzese M, Reni L, Schenone A, Mancardi GL, Primavera A: Multifocal motor neuropathy with conduction block after Campylobacter jejuni enteritis. Neurology 1997;48: 544.

33 Sugie K, Murata K, Ikoma K, Suzumura A, Takayanagi T: A case of acute multifocal motor neuropathy with conduction block after Campylobacter jejuni enteritis (in Japanese). Rinsho Shinkeigaku 1998;38:42-45.

34 Capasso M, Caporale CM, Pomilio F, Gandolfi P, Lugaresi A, Uncini A: Acute motor conduction block neuropathy. Another Guillain-Barré syndrome variant. Neurology 2003;61:617-622.

35 Terenghi F, Allaria S, Scarlato G, NobileOrazio E: Multifocal motor neuropathy and Campylobacter jejuni reactivity. Neurology 2002;59:282-284.

36 Kaji R, Bostock H, Kohara N, Murase N, Kimura J, Shibasaki H: Activity-dependent conduction block in multifocal motor neuropathy. Brain 2000;123:1602-1611.

37 Reiners K: Neurophysiologische und morphologische Aspekte der Nervenleitung. I. Grundlagen und Problematik des Leitungsblocks. Z EEG-EMG 1997:96-102. 
-38 Kaji R: Physiology of conduction block in multifocal motor neuropathy and other demyelinating neuropathies. Muscle Nerve 2003;27:285-296.

-39 Feasby TE, Brown WF, Gilbert JJ, Hahn AF: The pathological basis of conduction block in human neuropathies. J Neurol Neurosurg Psychiatry 1985;48:239-244.

40 Auer RN, Bell RB, Lee MA: Neuropathy with onion bulb formations and pure motor manifestations. Can J Neurol Sci 1989;16:194197.

41 Veugelers B, Theys P, Lammens M, Van Hees J, Robberecht W: Pathological findings in a patient with amyotrophic lateral sclerosis and multifocal motor neuropathy with conduction block. J Neurol Sci 1996;136:64-70.

-42 Priori A, Cinnante C, Pesenti A, Carpo M, Cappellari A, Nobile-Orazio E, Scarlato G, Barbieri S: Distinctive abnormalities of motor axonal strength-duration properties in multifocal motor neuropathy and in motor neurone disease. Brain 2002;125:24812490.

-43 Kaji R, Oka N, Tsuji T, Mezaki T, Nishio T, Akiguchi I, Kimura J: Pathological findings at the site of conduction block in multifocal motor neuropathy. Ann Neurol 1993;33:152158.

44 Bostock H, Sharief MK, Reid G, Murray NM: Axonal ion channel dysfunction in amyotrophic lateral sclerosis. Brain 1995;118:217225.

45 Burke D, Kiernan MC, Bostock H: Excitability of human axons. Clin Neurophysiol 2001; 112:1575-1585.

46 Kiernan MC, Guglielmi JM, Kaji R, Murray NM, Bostock H: Evidence for axonal membrane hyperpolarization in multifocal motor neuropathy with conduction block. Brain 2002; 125:664-675.

47 Ritchie JM, Straub RW: The hyperpolarization which follows activity in mammalian non-medullated fibres. J Physiol 1957;136: 80-97.

48 Raymond SA: Effects of nerve impulses on threshold of frog sciatic nerve fibres. J Physiol 1979;290:273-303.

-49 Kiernan MC, Bostock H: Effects of membrane polarization and ischaemia on the excitability properties of human motor axons. Brain 2000;123:2542-2551.

50 Kleinschnitz C, Reiners K: Multifokale motorische Neuropathie: Klinische Merkmale, Pathophysiologie und Therapie. Klin Neurophysiol 2006;37:169-179.

-51 Corbo M, Quattrini A, Lugaresi A, Santoro M, Latov N, Hays AP: Patterns of reactivity of human anti-GM1 antibodies with spinal cord and motor neurons. Ann Neurol 1992; 32:487-493.

-52 Thomas FP: Anti-Gm1 antibodies in motor system diseases and neuropathies (in German). Nervenarzt 1990;61:704-710.
53 Ogawa-Goto K, Funamoto N, Ohta Y, Abe T, Nagashima K: Myelin gangliosides of human peripheral nervous system: an enrichment of GM1 in the motor nerve myelin isolated from cauda equina. J Neurochem 1992;59: 1844-1849.

54 Paolazzi G, Peccatori S, Cavatorta FP, Morini A: A case of spontaneously recovering multifocal motor neuropathy with conduction blocks (MMNCB) during anti-TNF alpha therapy for ankylosing spondylitis. Clin Rheumatol 2009;28:993-995.

55 Santoro M, Uncini A, Corbo M, Staugaitis SM, Thomas FP, Hays AP, Latov N: Experimental conduction block induced by serum from a patient with anti-GM1 antibodies. Ann Neurol 1992;31:385-390.

56 Uncini A, Santoro M, Corbo M, Lugaresi A, Latov N: Conduction abnormalities induced by sera of patients with multifocal motor neuropathy and anti-GM1 antibodies. Muscle Nerve 1993;16:610-615.

57 Takigawa T, Yasuda H, Kikkawa R, Shigeta Y, Saida T, Kitasato $\mathrm{H}$ : Antibodies against GM1 ganglioside affect $\mathrm{K}^{+}$and $\mathrm{Na}^{+}$currents in isolated rat myelinated nerve fibers. Ann Neurol 1995;37:436-442.

58 Harvey GK, Toyka KV, Zielasek J, Kiefer R, Simonis C, Hartung HP: Failure of antiGM1 IgG or IgM to induce conduction block following intraneural transfer. Muscle Nerve 1995;18:388-394.

59 Hirota N, Kaji R, Bostock H, Shindo K, Kawasaki T, Mizutani K, Oka N, Kohara N, Saida T, Kimura J: The physiological effect of anti-GM1 antibodies on saltatory conduction and transmembrane currents in single motor axons. Brain 1997;120:2159-2169.

60 Benatar M: Antibodies from ALS patients inhibit dopamine release mediated by L-type calcium channels. Neurology 1999;52:15201521.

61 Quattrini A, Lorenzetti I, Sciorati C, Corbo M, Previtali SC, Feltri ML, Canal N, Wrabetz L, Nemni R, Clementi E: Human IgM antiGM1 autoantibodies modulate intracellular calcium homeostasis in neuroblastoma cells. J Neuroimmunol 2001;114:213-219.

62 Azulay JP, Rihet P, Pouget J, Cador F, Blin O, Boucraut J, Serratrice G: Long term follow up of multifocal motor neuropathy with conduction block under treatment. J Neurol Neurosurg Psychiatry 1997;62:391-394.

63 Leger JM, Chassande B, Musset L, Meininger $\mathrm{V}$, Bouche P, Baumann N: Intravenous immunoglobulin therapy in multifocal motor neuropathy: a double-blind, placebo-controlled study. Brain 2001;124:145-153.

64 Roberts M, Willison HJ, Vincent A, Newsom-Davis J: Multifocal motor neuropathy human sera block distal motor nerve conduction in mice. Ann Neurol 1995;38:111118 .
65 Pestronk A, Adams RN, Kuncl RW, Drachman DB, Clawson LL, Cornblath DR: Differential effects of prednisone and cyclophosphamide on autoantibodies in human neuromuscular disorders. Neurology 1989; 39:628-633.

66 Jaspert A, Claus D, Grehl H, Neundorfer B: Multifocal motor neuropathy: clinical and electrophysiological findings. J Neurol 1996; 243:684-692.

67 Katz JS, Wolfe GI, Bryan WW, Jackson CE, Amato AA, Barohn RJ: Electrophysiologic findings in multifocal motor neuropathy. Neurology 1997;48:700-707.

68 Kimura J: Principles and pitfalls of nerve conduction studies. Ann Neurol 1984;16: 415-429.

69 Taylor PK: CMAP dispersion, amplitude decay, and area decay in a normal population. Muscle Nerve 1993;16:1181-1187.

70 Rhee EK, England JD, Sumner AJ: A computer simulation of conduction block: effects produced by actual block versus interphase cancellation. Ann Neurol 1990;28:146-156.

71 Oh SJ, Kim DE, Kuruoglu HR: What is the best diagnostic index of conduction block and temporal dispersion? Muscle Nerve 1994;17:489-493.

72 Sumner AJ: Separating motor neuron diseases from pure motor neuropathies. Multifocal motor neuropathy with persistent conduction block. Adv Neurol 1991;56:399-403.

73 Lange DJ, Trojaborg W, McDonald TD, Blake DM: Persistent and transient 'conduction block' in motor neuron diseases. Muscle Nerve 1993;16:896-903.

74 Schulte-Mattler WJ, Muller T, Georgiadis D, Kornhuber ME, Zierz S: Length dependence of variables associated with temporal dispersion in human motor nerves. Muscle Nerve 2001;24:527-533.

-75 Cappellari A, Nobile-Orazio E, Meucci N, Levi Minzi G, Scarlato G, Barbieri S: Criteria for early detection of conduction block in multifocal motor neuropathy (MMN): a study based on control populations and follow-up of MMN patients. J Neurol 1997;244: 625-630.

76 Katz JS, Barohn RJ, Kojan S, Wolfe GI, Nations SP, Saperstein DS, Amato AA: Axonal multifocal motor neuropathy without conduction block or other features of demyelination. Neurology 2002;58:615-620.

77 Lewis RA: Multifocal motor neuropathy and Lewis Sumner syndrome: two distinct entities. Muscle Nerve 1999;22:1738-1739.

78 Cornblath DR, Sumner AJ: Conduction block in neuropathies with necrotizing vasculitis. Muscle Nerve 1991;14:185-186.

79 Corse AM, Chaudhry V, Crawford TO, Cornblath DR, Kuncl RW, Griffin JW: Sensory nerve pathology in multifocal motor neuropathy. Ann Neurol 1996;39:319-325.

$>80$ Krarup C, Stewart JD, Sumner AJ, Pestronk A, Lipton SA: A syndrome of asymmetric limb weakness with motor conduction block. Neurology 1990;40:118-127. 
-81 Jamieson PW, Giuliani MJ, Martinez AJ: Necrotizing angiopathy presenting with multifocal conduction blocks. Neurology 1991;41:442-444.

82 Homberg V, Reiners K, Toyka KV: Reversible conduction block in human ischemic neuropathy after ergotamine abuse. Muscle Nerve 1992;15:467-470.

83 Brown WF, Feasby TE: Conduction block and denervation in Guillain-Barré polyneuropathy. Brain 1984;107:219-239.

84 Research criteria for diagnosis of chronic inflammatory demyelinating polyneuropathy (CIDP). Report from an Ad Hoc Subcommittee of the American Academy of Neurology AIDS Task Force. Neurology 1991;41:617618.

85 Carpo M, Cappellari A, Mora G, Pedotti R, Barbieri S, Scarlato G, Nobile-Orazio E: Deterioration of multifocal motor neuropathy after plasma exchange. Neurology 1998;50: 1480-1482.

86 Arunachalam R, Osei-Lah A, Mills KR: Transcutaneous cervical root stimulation in the diagnosis of multifocal motor neuropathy with conduction block. J Neurol Neurosurg Psychiatry 2003;74:1329-1331.

87 Olney RK: Guidelines in electrodiagnostic medicine. Consensus criteria for the diagnosis of partial conduction block. Muscle Nerve 1999;8(suppl):S225-S229.

88 Nodera H, Bostock H, Izumi Y, Nakamura K, Urushihara R, Sakamoto T, Murase N, Shimazu H, Kusunoki S, Kaji R: Activity-dependent conduction block in multifocal motor neuropathy: magnetic fatigue test. Neurology 2006;67:280-287.

89 Deroide N, Uzenot D, Verschueren A, Azulay JP, Pouget J, Attarian S: Triple-stimulation technique in multifocal neuropathy with conduction block. Muscle Nerve 2007;35: 632-636.

90 Chaudhry V, Swash M: Multifocal motor neuropathy: is conduction block essential? Neurology 2006;67:558-559.

91 Pakiam AS, Parry GJ: Multifocal motor neuropathy without overt conduction block. Muscle Nerve 1998;21:243-245.

92 Ellis CM, Leary S, Payan J, Shaw C, Hu M, O'Brien M, Leigh PN: Use of human intravenous immunoglobulin in lower motor neuron syndromes. J Neurol Neurosurg Psychiatry 1999;67:15-19.

-93 Delmont E, Azulay JP, Giorgi R, Attarian S, Verschueren A, Uzenot D, Pouget J: Multifocal motor neuropathy with and without conduction block: a single entity? Neurology 2006;67:592-596.

94 Terenghi F, Cappellari A, Bersano A, Carpo $\mathrm{M}$, Barbieri S, Nobile-Orazio E: How long is IVIg effective in multifocal motor neuropathy? Neurology 2004;62:666-668.

95 Chaudhry V, Corse AM, Cornblath DR, Kuncl RW, Freimer ML, Griffin JW: Multifocal motor neuropathy: electrodiagnostic features. Muscle Nerve 1994;17:198-205.
$\$ 96$ Bech E, Jakobsen J, Orntoft TF: ELISA-type titertray assay of IgM anti-GM1 autoantibodies. Clin Chem 1994;40:1331-1334.

$\$ 97$ Pestronk A, Choksi R: Multifocal motor neuropathy. Serum IgM anti-GM1 ganglioside antibodies in most patients detected using covalent linkage of GM1 to ELISA plates. Neurology 1997;49:1289-1292.

$\$ 98$ Holloway RG, Feasby TE: To test or not to test? That is the question. Neurology 1999; 53:1905-1907.

$\$ 99$ McCombe PA, Wilson R, Prentice RL: Results of testing for anti-GM1 antibodies. J Clin Neurosci 2000;7:209-212.

100 Cavanna B, Carpo M, Pedotti R, Scarpini E, Meucci N, Allaria S, Scarlato G, NobileOrazio E: Anti-GM2 IgM antibodies: clinical correlates and reactivity with a human neuroblastoma cell line. J Neuroimmunol 1999;94:157-164.

101 Nobile-Orazio E, Gallia F, Terenghi F, Allaria S, Giannotta C, Carpo M: How useful are anti-neural IgM antibodies in the diagnosis of chronic immune-mediated neuropathies? J Neurol Sci 2008;266:156-163.

102 Latov N, Hays AP, Donofrio PD, Liao J, Ito $\mathrm{H}$, McGinnis S, Konstadoulakis M, Freddo L, Shy ME, et al: Monoclonal IgM with unique specificity to gangliosides GM1 and GD1b and to lacto-N-tetraose associated with human motor neuron disease. Neurology 1988;38:763-768.

103 Sadiq SA, Thomas FP, Kilidireas K, Protopsaltis $\mathrm{S}$, Hays AP, Lee KW, Romas SN, Kumar N, van den Berg L, Santoro M, et al: The spectrum of neurologic disease associated with anti-GM1 antibodies. Neurology 1990;40:1067-1072.

104 Lamb NL, Patten BM: Clinical correlations of anti-GM1 antibodies in amyotrophic lateral sclerosis and neuropathies. Muscle Nerve 1991;14:1021-1027.

105 Hughes RA, Hadden RD, Gregson NA, Smith KJ: Pathogenesis of Guillain-Barré syndrome. J Neuroimmunol 1999;100:7497.

- 106 van Schaik IN, Bossuyt PM, Brand A, Vermeulen M: Diagnostic value of GM1 antibodies in motor neuron disorders and neuropathies: a meta-analysis. Neurology 1995; 45:1570-1577.

107 Alaedini A, Sander HW, Hays AP, Latov N: Antiganglioside antibodies in multifocal acquired sensory and motor neuropathy. Arch Neurol 2003;60:42-46.

108 Taylor BV, Gross L, Windebank AJ: The sensitivity and specificity of anti-GM1 antibody testing. Neurology 1996;47:951955

109 Freddo L, Yu RK, Latov N, Donofrio PD, Hays AP, Greenberg HS, Albers JW, Allessi AG, Keren D: Gangliosides GM1 and GD1b are antigens for IgM M-protein in a patient with motor neuron disease. Neurology 1986;36:454-458.
110 Donaghy M, Mills KR, Boniface SJ, Simmons J, Wright I, Gregson N, Jacobs J: Pure motor demyelinating neuropathy: deterioration after steroid treatment and improvement with intravenous immunoglobulin. J Neurol Neurosurg Psychiatry 1994;57:778783.

111 Taylor BV, Dyck PJ, Engelstad J, Gruener G, Grant I, Dyck PJ: Multifocal motor neuropathy: pathologic alterations at the site of conduction block. J Neuropathol Exp Neurol 2004;63:129-137.

112 Van Es HW, Van den Berg LH, Franssen H, Witkamp TD, Ramos LM, Notermans NC, Feldberg MA, Wokke JH: Magnetic resonance imaging of the brachial plexus in patients with multifocal motor neuropathy. Neurology 1997;48:1218-1224.

113 Parry GJ: AAEM case report \#30: multifocal motor neuropathy. Muscle Nerve 1996; 19:269-276.

114 Duggins AJ, McLeod JG, Pollard JD, Davies L, Yang F, Thompson EO, Soper JR: Spinal root and plexus hypertrophy in chronic inflammatory demyelinating polyneuropathy. Brain 1999;122:1383-1390.

115 Joint Task Force of the EFNS and the PNS: European Federation of Neurological Societies/Peripheral Nerve Society Guideline on management of paraproteinemic demyelinating neuropathies. Report of a joint task force of the European Federation of Neurological Societies and the Peripheral Nerve Society. J Peripher Nerv Syst 2006;11: 9-19.

-116 Traynor BJ, Codd MB, Corr B, Forde C, Frost E, Hardiman O: Amyotrophic lateral sclerosis mimic syndromes: a populationbased study. Arch Neurol 2000;57:109113.

117 van den Berg-Vos RM, Visser J, Franssen H, de Visser M, de Jong JM, Kalmijn S, Wokke $\mathrm{JH}$, van den Berg LH: Sporadic lower motor neuron disease with adult onset: classification of subtypes. Brain 2003;126:10361047.

118 Verschueren A, Azulay JP, Attarian S, Boucraut J, Pellissier JF, Pouget J: Lewis-Sumner syndrome and multifocal motor neuropathy. Muscle Nerve 2005;31:88-94.

119 Hughes RA: The spectrum of acquired demyelinating polyradiculoneuropathy. Acta Neurol Belg 1994;94:128-132.

120 Oh SI, Claussen GC, Kim DS: Motor and sensory demyelinating mononeuropathy multiplex (multifocal motor and sensory demyelinating neuropathy): a separate entity or a variant of chronic inflammatory demyelinating polyneuropathy? J Peripher Nerv Syst 1997;2:362-369.

121 Saperstein DS, Amato AA, Wolfe GI, Katz JS, Nations SP, Jackson CE, Bryan WW, Burns DK, Barohn RJ: Multifocal acquired demyelinating sensory and motor neuropathy: the Lewis-Sumner syndrome. Muscle Nerve 1999;22:560-566. 
-122 Viala K, Renie L, Maisonobe T, Behin A, Neil J, Leger JM, Bouche P: Follow-up study and response to treatment in 23 patients with Lewis-Sumner syndrome. Brain 2004; 127:2010-2017.

-123 Lambrecq V, Krim E, Rouanet-Larriviere M, Lagueny A: Sensory loss in multifocal motor neuropathy: a clinical and electrophysiological study. Muscle Nerve 2009;39: 131-136.

-124 Beydoun SR: Multifocal motor neuropathy with conduction block misdiagnosed as multiple entrapment neuropathies. Muscle Nerve 1998;21:813-815.

-125 Van den Berg LH, Lokhorst H, Wokke JH: Pulsed high-dose dexamethasone is not effective in patients with multifocal motor neuropathy. Neurology 1997;48:1135.

-126 Lehmann HC, Hoffmann FR, Fusshoeller A, Meyer zu Horste G, Hetzel R, Hartung HP, Schroeter M, Kieseier BC: The clinical value of therapeutic plasma exchange in multifocal motor neuropathy. J Neurol Sci 2008;271:34-39.

$\checkmark 127$ Azulay JP, Blin O, Pouget J, Boucraut J, Bille-Turc F, Carles G, Serratrice G: Intravenous immunoglobulin treatment in patients with motor neuron syndromes associated with anti-GM1 antibodies: a double-blind, placebo-controlled study. Neurology 1994;44:429-432.

-128 Federico P, Zochodne DW, Hahn AF, Brown WF, Feasby TE: Multifocal motor neuropathy improved by IVIg: randomized, double-blind, placebo-controlled study. Neurology 2000;55:1256-1262.

-129 Donofrio PD, Berger A, Brannagan TH, 3rd, Bromberg MB, Howard JF, Latov N, Quick A, Tandan R: Consensus statement: the use of intravenous immunoglobulin in the treatment of neuromuscular conditions report of the AANEM ad hoc committee. Muscle Nerve 2009;40:890-900.

-130 Slee M, Selvan A, Donaghy M: Multifocal motor neuropathy: the diagnostic spectrum and response to treatment. Neurology 2007;69:1680-1687.

-131 Leger JM, Viala K, Cancalon F, Maisonobe T, Gruwez B, Waegemans T, Bouche P: Intravenous immunoglobulin as short- and long-term therapy of multifocal motor neuropathy: a retrospective study of response to IVIg and of its predictive criteria in 40 patients. J Neurol Neurosurg Psychiatry 2008;79:93-96.
132 Eftimov F, Vermeulen M, de Haan RJ, van den Berg LH, van Schaik IN: Subcutaneous immunoglobulin therapy for multifocal motor neuropathy. J Peripher Nerv Syst 2009; 14:93-100.

133 Dimberg EL: Treatment of multifocal motor neuropathy with immunoglobulin: does route of administration matter? Eur J Neurol 2009; 16:553-554.

134 Harbo T, Andersen H, Hess A, Hansen K, Sindrup SH, Jakobsen J: Subcutaneous versus intravenous immunoglobulin in multifocal motor neuropathy: a randomized, single-blinded cross-over trial. Eur J Neurol 2009; 16:631-638.

135 Stangel M, Hartung HP, Marx P, Gold R: Intravenous immunoglobulin treatment of neurological autoimmune diseases. J Neurol Sci 1998;153:203-214.

136 Comi G, Amadio S, Galardi G, Fazio R, Nemni R: Clinical and neurophysiological assessment of immunoglobulin therapy in five patients with multifocal motor neuropathy. J Neurol Neurosurg Psychiatry 1994; 57(suppl):35-37.

137 Cappellari A, Nobile-Orazio E, Meucci N, Scarlato G, Barbieri S: Multifocal motor neuropathy: a source of error in the serial evaluation of conduction block. Muscle Nerve 1996;19:666-669.

138 Meucci N, Cappellari A, Barbieri S, Scarlato $G$, Nobile-Orazio E: Long term effect of intravenous immunoglobulins and oral cyclophosphamide in multifocal motor neuropathy. J Neurol Neurosurg Psychiatry 1997;63:765-769.

139 Van den Berg LH, Franssen H, Wokke JH: The long-term effect of intravenous immunoglobulin treatment in multifocal motor neuropathy. Brain 1998;121:421-428.

140 Van den Berg-Vos RM, Franssen H, Wokke JH, Van den Berg LH: Multifocal motor neuropathy: long-term clinical and electrophysiological assessment of intravenous immunoglobulin maintenance treatment. Brain 2002;125:1875-1886.

- 141 Baumann A, Hess CW, Sturzenegger M: IVIg dose increase in multifocal motor neuropathy: a prospective six month follow-up. J Neurol 2009;256:608-614.
142 Vucic S, Black KR, Chong PS, Cros D: Multifocal motor neuropathy: decrease in conduction blocks and reinnervation with long-term IVIg. Neurology 2004;63:12641269.

143 Pringle CE, Belden J, Veitch JE, Brown WF: Multifocal motor neuropathy presenting as ophthalmoplegia. Muscle Nerve 1997;20: 347-351.

144 Brannagan TH 3rd, Alaedini A, Gladstone DE: High-dose cyclophosphamide without stem cell rescue for refractory multifocal motor neuropathy. Muscle Nerve 2006;34: 246-250.

145 Axelson HW, Oberg G, Askmark H: No benefit of treatment with cyclophosphamide and autologous blood stem cell transplantation in multifocal motor neuropathy. Acta Neurol Scand 2008;117:432-434.

146 Martina IS, van Doorn PA, Schmitz PI, Meulstee J, van der Meche FG: Chronic motor neuropathies: response to interferonbetala after failure of conventional therapies. J Neurol Neurosurg Psychiatry 1999; 66:197-201.

147 Nemni R, Santuccio G, Calabrese E, Galardi G, Canal N: Efficacy of cyclosporine treatment in multifocal motor neuropathy. J Neurol 2003;250:1118-1120.

148 Piepers S, Van den Berg-Vos R, Van der Pol WL, Franssen H, Wokke J, Van den Berg L: Mycophenolate mofetil as adjunctive therapy for MMN patients: a randomized, controlled trial. Brain 2007;130:2004-2010.

149 Umapathi T, Hughes RA, Nobile-Orazio E, Léger JM: Immunosuppressant and immunomodulatory treatments for multifocal motor neuropathy. Cochrane Database Syst Rev 2009; 1:CD003217.

150 Rojas-Garcia R, Gallardo E, de Andres I, de Luna N, Juarez C, Sanchez P, Illa I: Chronic neuropathy with IgM anti-ganglioside antibodies: lack of long term response to rituximab. Neurology 2003;61:1814-1816.

151 Pestronk A, Florence J, Miller T, Choksi R, Al-Lozi MT, Levine TD: Treatment of IgM antibody associated polyneuropathies using rituximab. J Neurol Neurosurg Psychiatry 2003;74:485-489.

-152 Stieglbauer K, Topakian R, Hinterberger G, Aichner FT: Beneficial effect of rituximab monotherapy in multifocal motor neuropathy. Neuromuscul Disord 2009;19:473475 . 